\title{
M. Sharapova and the meldonium scandal: anti- crisis communications in personal branding
}

\author{
Alexandra Zaharova ${ }^{1, *}$, and Elena Karmalova ${ }^{2}$ \\ "Novosibirsk State Technical University", Russia \\ ${ }^{2}$ Federal State Budget Educational Institution of Higher Education «Saint-Petersburg State University \\ of Economics», Russia
}

\begin{abstract}
The article simulates and analyzes a practical case of building anti-crisis communications by tennis player Maria Sharapova in the meldonium scandal. The factors of the development of the crisis are analyzed, strategic and tactical mistakes and blunders are revealed, strategic and tactical successes and achievements are indicated.
\end{abstract}

Anti-crisis management and anti-crisis communications in the situation of the COVID-19 pandemic have become especially relevant for business, the social sphere and society as a whole. Before the pandemic crisis, the problem was perceived as important primarily by businesses and structures associated with potential emergencies. In the field of personal branding, anti-crisis communications are generally poorly understood, but today the need for anti-crisis programs and measures is not disputed in any area of activity. The successful anti-crisis case "Maria Sharapova and meldonium", modeled and analyzed, and can become a successful algorithm for practical actions both in the field of anti-crisis communications of personal branding and in the field of sports anti-crisis. The latter area seems to be very crisis-intensive for various reasons.

To date, there are no detailed studies devoted to the problem of anti-crisis communications in the field of personal branding or sports. We can only talk about a fairly well developed area of research - anti-crisis communications in business. Classic foreign research in this area - M. Rogester, «Crisis Management. What to do when the unthinkable happens» (1989), not translated into Russian, and PF Seitel, «The Practice of Public Relations» (N.Y., 1992). It was published in Russian translation in 2002 [1]. T. Coombs, analyzing the works of other scientists, points out in his work «The Handbook of Crisis Communication» that any crisis is, first of all, a kind of turning point, the result of which can be both damage and change for the better [2].

Anti-crisis PR is a part of anti-crisis management. According to T. Coombs, today anticrisis management has moved away from the fact that it is only necessary to prepare for crises and wait, now management consists of four main elements: prevention; preparation; reactions; revisions [3]. The researcher also suggests strategies for coping with crises and signs of a crisis response. Foreign scientists talk about the main mistakes that companies make during crises [4].

\footnotetext{
${ }^{*}$ Corresponding author: sah31zah@mail.ru
} 
Among Russian authors, the most significant contribution to the formation of anticrisis PR communication as a scientific and educational discipline was made by such authors as A. N. Chumikov [5], S. M. Emelyanov [6], D. P. Gavra. A. N. Chumikov mostly researches anti-crisis communications in emergencies. D.P. Gavre clarifies the definitions of T. Coombs and K. Firn-Banks as the most significant in anti-crisis PR, in collaboration with E. V. Bykova they consider the applied aspects of anti-crisis communications, for example, crisis communications in construction [7]. In the last decade, works have appeared on the reputation of public companies on the Internet. The Internet with social networks and blogs is both a threat and an opportunity for organizations and crisis communications, according to O. Golub [8].

The purpose of our study was to analyze the anti-crisis communications used for the personal brand of Maria Sharapova in the situation with meldonium and disqualification in 2016-2018. In modeling this crisis, we used the so-called case methodology, known in the domestic anti-crisis PR since the article by A. G. Kvyat [9]. The hypothesis of our research is that effective anti-crisis communications not only solve situational problems: in the case of Sharapova, this is a significant reduction in the period of ineligibility, but also contribute to maintaining the image and reputation of the personal brand: here, in our opinion, this fact is evidenced by the tennis player's advertising contracts and besides, maintaining the loyalty of the fans in relation to her.

In accordance with the case-study method, we gave a brief description of the crisis. Maria Sharapova is the most titled Russian tennis player, the former first racket of the world. In March 2016, she called an emergency press conference where she announced that she had failed a doping test. Meldonium was found in her samples. Without carefully reading the documents sent from the World Anti-Doping Organization, she continued to take meldonium in connection with her existing heart problems and potential diabetes. Sharapova was disqualified, but not for 4 years, as originally planned, but only for 15 months.

Further, it is necessary to reproduce the entire chronology of the crisis and provide parallel monitoring of the media and social networks, which in the framework of this publication we can do only partially, showing a representation of its beginning and end. In early March 2016, Maria Sharapova wrote on her Twitter that she was going to hold an online press conference in the next few hours, which anyone can watch on her official website. The public speculated that Maria wanted to pause or end her career altogether.

An online press conference was held on March 7 of 2016. Sharapova said that she received a letter from the International Tennis Federation stating that she had failed a doping test. Her sample was found to contain meldonium, which has been banned since January 1 of 2016. The athlete did not accuse anyone, reported her violation. In general, she spoke about the situation and explained the reasons for the violation, saying that she wanted to speak openly and honestly. On June 8 of 2016, Maria Sharapova was disqualified for 2 years. The disqualification was supposed to take effect on January 26 and last until January 25 of 2018.

On April 26 of 2017, the period of disqualification of Maria Sharapova ended.

On October 15 of 2017, the Women's Tennis Association (WTA) Tournament in Tianjin in China ended with the victory of Maria Sharapova, who defeated Belarusian Arina Sobolenko in the final in two difficult sets. Having won his 36th career title and the first since May 2015, the ex-first racket of the world goes to Moscow, where on Tuesday she is to play her first match at the VTB Kremlin Cup tournament. In her asset was the first title since May 2015 and 36th in her career, which will allow her to rise in the ranking to 57th place on Monday [10].

On May 18, 2018, the ongoing Internazionali BNL D'Italia, the \$ 3.5 million Women's Tennis Association (WTA) tournament in Rome, was the biggest success for Maria 
Sharapova since the end of her Meldonium suspension last April. Having beaten the sixth racket of the world Elena Ostapenko from Latvia in 3 hours 10 minutes, the 31 -year-old Russian woman made her way to the semifinals and returned to the top thirty of the world rankings, which guarantees her a place in the «seed» in the Roland Garros draw [11].

Thus, even a significantly shortened version of the chronology of the development of the crisis demonstrates that thanks to effective anti-crisis communications, the period of Sharapova's disqualification was significantly reduced, instead of 4 years, it lasted just over a year, and already in the same 2017 , the tennis player began to play.

Several parameters are important for the analysis of any anti-crisis situation. The first of them is the factors of the development of the crisis. Undoubtedly, they primarily depend on the scope of the company, in our case, the personal sports brand. We have identified four main factors, realizing that the list is not exhaustive.

1. Anti-doping fight in world sport. In recent years, there has been a serious struggle for «clean» sports and everything related to illegal drugs is treated very strictly. As we now know, after the «Meldonium crisis» Russian athletes were overtaken by «Rodchenkov's report». At the same time, in the spring of 2016, the World AntiDoping Agency announced that it could appeal to the Court of Arbitration for Sport if the decision of the International Tennis Federation on the period of Sharapova's disqualification is too lenient. True, despite the fact that instead of the planned 4 years, Sharapova was disqualified for only 15 months, WADA did not file an appeal.

2. Tough competition in the tennis environment. The background of Sharapova is serious, but here the voices of the former defendants in doping scandals are heard, who received the appropriate punishment, and they see concessions in reducing the period of disqualification for Sharapova.

3. Ambiguous assessment of the act of Sharapova by colleagues. Judging by the reviews, Maria Sharapova does not maintain connections within the tennis gettogether, preferring to communicate and be friends outside of her professional environment. The leaders of the female and male ratings at that time, Serena Williams and Novak Djokovic, expressed sympathy and support for Maria. At the same time, Nadal and Murray spoke out rather harshly, saying that such antics deal a blow to the whole sport and tennis in particular.

4. Large number of stakeholders:

- athletes, including tennis players,

- fans,

- sports officials,

- sponsors,

- media.

The main forces of Sharapova's team were immediately thrown at the fans, which is good, but clearly not enough. We think the target audience of tennis experts has been overlooked. In general, the identification of strategic and tactical mistakes and blunders because of the analysis of the crisis is the second parameter of the case. We have identified the following:

1. It is possible that up to a certain point the proactive strategy and comments on social media of each stage of disqualification were correct and effective. But at some point, PR experts felt that it was undesirable for Sharapova to comment on the situation anymore. She has already done everything that depended on her as a public speaker.

2. Lack of tennis experts in the information field. Tennis players and other athletes, fans, sports officials, journalists were involved in the situation, but to a much lesser extent experts. Their function is indicated by us in the previous paragraph. 
3. The almost complete absence of data in the information field for evaluating the drug meldonium, that it does not affect the achievement of results.

4. Comments of the athlete herself that she allegedly did not know about the notifications about the ban on taking Mildronate from January 1 of 2016. Her Facebook explanations to fans were not convincing. Although Sharapova completely took the blame on herself, there is no doubt a large team working with her, in which there are people responsible for this.

5. The majority of fellow tennis players perceived the situation with doping as an opportunity to reproach the athlete with arrogance and unwillingness to communicate within the tennis community.

At the same time, in the work of the anti-crisis team of the tennis player and Maria herself, who spoke on her behalf both in social media and in various formats of relations with the media, there were many strategic and tactical successes and achievements.

1. Maria Sharapova had the right image and reputation before the crisis. She has established herself as a talented athlete who achieves everything with her work. The tennis player participated in public life, was engaged in charity work. Summing up, we note that Maria Sharapova at that time, undoubtedly, had a developed personal brand.

2. Correctly conducted anti-crisis communication also contributed to this. The team's reaction to the crisis was anticipatory and instantaneous: during this period, the work was carried out 24/7 with a round-the-clock mode of information transparency of the athlete for the media, fan clubs, fans, sponsors, etc.

3. In addition, she took advantage of the potential of new media. The press conference with the tennis player could be watched online, the work was carried out through the website, through social networks and messengers (mostly through Facebook and Twitter, as well as Instagram); messages from a personal account acted very positively, correspondence directly with an interested person always appeals to the public. Quick replies to social media posts remove negative emotions and comments at the stage of their occurrence.

4. Sharapova used the personification of comments, eliminating impersonality. Here we will once again recall the use of a personal account: it was clear that this is really the personal opinion of the person concerned, and not some text written for him. This helps to get the support of the Internet audience: wishes «not to give up», «to win», «not to lose heart», etc.

5. The team built communication according to the principles of storytelling. Any crisis is a story that has its own stages of development. At each stage there should be informational reasons so as not to lose interest from the mass audience, including the media. The sportswomen's PR specialists tried to set the discussion discourse themselves so that they could control the information flow.

6. Communication experts advise that after the crisis is over, it is necessary to launch a communication campaign that would include gratitude to those who helped to overcome this period (fans, interested online community, sponsors, etc.). Note that here Sharapova's team played ahead of the curve and used this technology in the process of deploying anti-crisis activities.

Our analysis of the media and public opinion in the situation with the disqualification and return of Maria Sharapova to tennis clearly indicates that «Maria Sharapova» is a large brand, like all the stars of big sports. At the same time, as we wrote earlier, Sharapova's real sports achievements are monetized much less than the loyalty of consumers and advertisers in relation to her. Summarizing the use of anti-crisis PR technologies by Maria Sharapova's team, we note that anti-crisis and post-crisis communication not only took place, but were also bright. 
During a crisis, the maximum attention is riveted to the athlete. It is necessary to use this time to solve communication problems and reduce communication gaps. During this period, you can talk about the values of the athlete, draw attention to his merits outside of sports life (for example, doing charity work). During her disqualification, the information field of Maria Sharapova was characterized by not only topics of charity, promoting the Shugarpova brand, but also studying at Harvard under the MBA program, creating and publishing a book, and other informational reasons.

It seems to us that this direction of anti-crisis PR has interesting development prospects, firstly, due to the insufficient study of anti-crisis communications both in sports PR and in personal branding. Secondly, due to the high intensity of the crisis in both areas. The accumulation and analysis of relevant content will allow us to go beyond cases of success stories, it will be possible to talk about modeling anti-crisis programs and actions.

\section{References}

1. F. P. Satel, Contemporary Public Relations, Fraser P. Satel; Tr. from English [ABOUT. V. Dubitskaya and others], 8th ed., M: Consulting group "Image-Contact": Infra-M. 590 (2002)

2. W. T. Coombs, S. J. Holladay (ed.), The handbook of crisis communication, John Wiley \& Sons, V. 22.P. 132 (2011).

3. T. Coombs, Ongoing crisis communication. Planning, managing, and responding. Thousand Oaks: Sage Publications. p. 6 (2007).

4. R. Ulmer, T. Sellnau, M. Seeger, Effective Crisis Communication: From Crisis to Opportunity / ed. A.A. Kiseleva; lane from English. $-\mathrm{Kh} . \therefore$ Humanitarian Center Publishing House. pp. 68-69 (2011).

5. A. N. Chumikov, Anti-crisis communications: a textbook for university students studying in the direction of training (specialty) "Advertising and public relations", Moscow: Aspect Press, 172, (2013)

6. SM Emelyanov, Theory and practice of public relations: a textbook for academic bachelor's degree, ed., Rev. and add. - Moscow: Yurayt Publishing House, 231 p (2018).

7. D. P. Gavra, E. V. Bykova, To rethinking the category of crisis communication, Strategic communications in business and politics: materials of an international scientific conference. p. 23. (2013).

8. O. Yu. Golub, Communication in crisis situations: models of Internet presence, Bulletin of the Saratov University. New series. Series: Sociology. Political science, T.14, No. 4, P. 12. (2014).

9. A. G. Kvyat, Overcoming the Reputational Crisis on the Example of LLC "Darina" (case study). [Online]. Available at: http://www.mediascope.ru/node/1124

10. Maria Sharapova goes to Moscow with a victory. [Online]. Available at: https://www.kommersant.ru/doc/3440236

11. Maria Sharapova pleased herself with Rome [Online]. Available at: https://www.kommersant.ru/doc/3634490 